\title{
THE BIOLOGICAL EFFECTS OF IONISING RADIATION ON THE THYROID GLAND
}

\author{
J. R. Philp, B.Sc., M.B., Ch.B. \\ Research Fellow, Department of Materia Medica and Therapeutics, University of Aberdeen.
}

SINCE the high incidence of iatrogenic hypothyroidism $(40 \%$ eight years after treatment) in thyrotoxic patients treated with radioiodine was appreciated, the radiobiology of the thyroid gland has become a subject of great clinical importance. The method of treatment in its orthodox form and dosage is clearly unsatisfactory and efforts are being made to improve it in various centres. Unfortunately, these efforts are having to take place against a background of inadequate information about fundamental radiobiological mechanisms.

It is my intention to review some of the literature relevant to the radiobiology of the thyroid but before doing so I would like to mention some common radiobiological concepts.

The events following bombardment of a tissue by ionising radiation are discussed by Bacq and Alexander (1961). When X-rays or $\gamma$-rays enter a tissue they eject electrons from the atoms by which they are absorbed. These ejected electrons in turn eject electrons from other atoms and are responsible for most of the ionisations which occur. In the case of $\alpha$-rays, $\beta$-rays, protons and neutrons electrons are again ejected with similar consequences.

It should be noted that molecules can be damaged directly or indirectly by ionisation. Direct damage results when the molecule is ionised by the passage of an ionising particle through it. Indirect damage can also result if the molecules are dissolved in water which can be ionised to form free radicals which react with the molecules with consequent changes in their physico-chemical nature and function. In biological systems where water is the universal solvent indirect damage from free radicals is probably the most important.

Doses of radiation are measured by the amount of radiation absorbed by the tissue in rads where one rad is equivalent to 100 ergs of absorbed energy per gram of tissue. Dose responses are often expressed in terms of the $D_{37}$ dose where one $D_{37}$ leaves $37 \%$ of the radio- biological targets undamaged, e.g. $37 \%$ of cells in a population able to divide or function etc. In theory loss of ability to survive or function or divide may result from entirely different combinations of damaged molecular sites within the cell. In general it seems reasonable to suppose that for reproduction, long term survival and function chromosal damage is important. Presumably, damage to individual enzymes and other cytoplasmic structures can be made good providing the appropriate genes remain intact.

\section{Human and Clinical Studies}

External radiation was once used extensively in the treatment of thyrotoxicosis and many reports exist claiming that the disease could be cured by this means. Hayes (1927) claimed $62 \%$ of his cases were cured and that $14 \%$ were improved. Groover, Christie, Merritt, Coe \& McPeak (1929) claimed an $89 \%$ cure rate and $9 \%$ improved. Hayes (1927) warned of the possibility of inducing hypothyroidism by radiation overdosage but gives no indication of the incidence of this occurrence. Unfortunately it is impossible in many cases to ascertain what rad dose the patients received as often complete physical details of the $X$-ray machine and procedure are not supplied. Furthermore, in all cases the total doses were fractionated over several weeks and calculation of the one dose equivalent is impossible. It is estimated by Goolden (1964) that the cumulative dose could not have exceeded 3,500 roentgens. It is of interest that in twenty cases of laryngeal cancer treated bv large doses of X-ravs in which there was inevitable exposure of the thyroid gland there were no cases of hynothvroidism $1 \frac{1}{3}$ to 12 vears later. (Greig, Boyle, Buchanan and Fulton. 1965).

Radioiodine when it was introduced by Hertz in 1941 offered a golden therapeutic onportunity. Here was an agent which could seek out its own target and then destrov it. the deoree of destruction, it was thought, being proportional 
to the millicurie dose administered. Numerous trials of this agent have been reported. In the series reported by Greig, Crooks \& Macgregor, (1966), $38 \%$ remained thyrotoxic and $25 \%$ became hypothyroid with one dose. Of those requiring a second dose $(38 \%), 37 \%$ remained thyrotoxic, $29 \%$ became euthyroid, and $27 \%$ became hypothyroid. Occasionally three or four doses were required. The incidence of recurrence of hyperthyroidism with radioiodine therapy is therefore low but the incidence of hypothyroidism is very high and increases with the number of doses given and the length of time after treatment. The same pattern has been reported by Beling \& Einhorn (1961), Dunn \& Chapman (1964), Green \& Wilson (1964) and McGirr, Thompson \& Murray (1964). The situation was summarised by Crooks (1965). In his series of patients $40 \%$ were hypothyroid some 8 vears after therapy with no evidence of a plateau having been reached in the cumulative incidence. A trial of a lower dose regime of ${ }^{131}$ I has been reported by Smith \& Wilson (1965). They gave "calculated rad doses" of "3.500 rads" in contrast to orthodox levels of "7.000 to 10.000 rads". This procedure lowered the incidence of hvnothyroidism at 4 years after therapy from $28 \%$ to $9 \%$. However it remains to be seen if a stable plateau will be reached. Furthermore. as a result of the lower dose employed there is a delay in the attainment of the euthyroid state and antithyroid drugs have been required in a higher proportion $(60 \%)$ of patients.

These clinical observations point to the basic conflict in radioiodine therapy, i.e. that high doses effect rapid control but cause a high hypothyroid rate; lowering the dose decreases the hypothyroid rate but lengthens the period for control of symptoms unless antithyroid drugs are used. In the case of deliberately induced mild hypothyroidism in patients with angina pectoris the conflict disappears as this result can almost be guaranteed (Blumgart, Freedburg \& Buka, 1948; Blumgart, Freedburg \& Kurland, 1955). In general, however, the dose required is huge (e.g. 50 millicuries) compared to that normallv used in the treatment of thyrotoxicosis (5-15 millicuries). This difference probably results from the higher nercentage uptake of the administered dose by the cells of the thyrotoxic gland. On the other hand as yet unknown biological nhenomena may be operating to produce this disparity in apparent radiosensitivity.

These clinical effects are in line with studies of the function and histology of the radioiodinetreated human thyroid gland. The functional changes have been described by Dobyns, Vickery, Maloof \& Chapman (1953) and Eckert, Green, Kilpatrick \& Wilson (1960). In patients rendered euthyroid the absolute uptake of a tracer dose of radioiodine is within the normal range although the residual tissue remains overactive as evidenced by a high turnover rate of the tracer. The response to TSH is reduced and there is little suppression of thyroid function by triiodothyronine. That the functional reserve is reduced is demonstrated by the ease with which the serum PBI can be lowered by antithyroid drug administration. These findings are in sharp contrast to the behaviour of the remnant after partial thyroidectomy which after a period of five years often comes to resemble the normal thyroid both functionally and histologically. The histological changes in the radioiodine-treated cases are compatible with the observations on function and have been described by Dobyns and others (1953), Freedburg. Kurland \& Blumgart (1953), Lindsay, Dailey \& Jones (1954) and Curran, Eckert \& Wilson (1958). The acute changes consist of nuclear pyknosis, cell death, small vessel thrombosis and oedema of the stroma. In the long term there are small islands of functioning cells embedded in large volumes of fibrous tissue. The follicles are small and irregular with little colloid storage; the follicular cells are large and many of them have bizarre nuclear forms.

In none of these series were malignant cells observed in the histological sections. In adults no significant incidence of thyroid cancer has been found either after external X-ray therapy (Quimby \& Werner, 1949), or after radioiodine therapy (Hollingworth, Hamilton, Tamagaki \& Beebe, 1963). In children and adolescents, however, a definite association between external irradiation of the neck and the subsequent development of thyroid cancer has been established (Goolden, 1964). It has also been suggested by Sheline, Lindsay and Bell (1959) that thyroid cancer may follow the use of radioiodine for treating hyperthyroidism in childhood. In Doniach's animal experiments (1953) a significant number of rats developed thyroid carcinoma after being treated with low doses $(5$ to $30 \mu \mathrm{c})$ of ${ }^{131}$ I followed by methylthiouracil. No such tumours were found in a group of rats given $100 \mu \mathrm{c}^{131} \mathrm{I}$. One possible interpretation of this phenomenon is that all doses of radiation cause cancerous mutations but with really high doses the cancer cells are rendered incapable of division. It should be noted, however, that Goldberg and Chaikoff (1952) described thy- 
roid cancer in rats within two years of their receiving $400 \mu \mathrm{c}$ of ${ }^{131} \mathrm{I}$.

Another possible biological hazard of radioiodine therapy is leukaemogenesis but as yet no significant incidence of this has been reported (Pochin 1960; Green, Fisher, Miller \& Wilson, 1961; and Werner, Gittelshon \& Brill, 1961). Similarly no significant incidence of congenital malfunctions has been found in the children of mothers treated with radioiodine (Means, Degroot \& Stanbury, 1963). Clearly, however, both these hazards merit further investigation.

The idea of radioiodine therapy is to achieve a "radiation partial thyroidectomy", but it remains to be seen if this is possible within a reasonable period of time. Clinical trials so far have not been conclusive and it is more likely that the solution will come from purer radiobiological situations in which fundamental changes in cell behaviour following irradiation can be assessed in a quantitative manner.

\section{In Vivo Studies of the Radiobiology of the Thyroid in Animals}

Very little truly quantitative information is available on the radiobiology of organised tissues. Walters, Anson \& Ivey (1931) found no changes in the thyroids of dogs treated with doses of X-rays similar to those used in the treatment of thyrotoxicosis. Levene, Gould \& Kniseley (1955) studied the qualitative histological effects of large doses of ${ }^{131}$ I given to dogs. From the fourth day onwards after the administration of ${ }^{131} \mathrm{I}$ there was a rapid loss of radioactivity from the gland and a rise in the bound plasma radioactivity. By the twelfth day there was very little radioactivity left in the gland. These changes were explained by the histological and radioautographic observations. As found in humans there was an initial patchy distribution of ${ }^{131} \mathrm{I}$ throughout the gland. No histological changes were observed during the first three days after radioiodine administration. By the sixth day there was massive necrosis in the central part of the gland from which nearly all radioactivity had been lost. However the isotope was still concentrated in a peripheral rim of histologically intact follicles. From the twelfth day even this rim of "intact" tissue had disappeared and the radioiodine was only concentrated in small islands of functioning cells throughout the gland. In this complex situation no accurate assessment of radiation dose is possible. Similar studies in rats by Findlay \& Leblond (1948) and Goldberg, Chaikoff, Lind- say \& Feller (1950) have yielded similar results. In order to quantitate the dose of radiation, St. Aubin, Kniseley and Andrews (1955) studied the effect of external radiation in the thyroid histology and ${ }^{131} I$ metabolism in the dog. With a dose of 21,000 rads they found almost identical results to those obtained by Levene and others (1955), i.e. accelerated release of ${ }^{131} \mathrm{I}$ (tracer dose) from the fourth day onwards accompanied by gross central necrosis with the same surviving rim of follicles at the periphery of the gland. This suggests a biological explanation (e.g. blood vessel necrosis) for these phenomena. The latent period of three days in both cases before histological and functional changes occur argues against the theory that in the case of 131I, time is needed for the cumulative radiation dose to build up. Although changes similar to these were observed with 10,000 rads they were surprisingly of minimal degree. This small histological and functional response to a massive dose $(10,000$ rads) of X-rays is borne out by the electron microscope studies of McQuade, Seaman \& Porporis (1956) in which no changes were found within 6 hours of a 17,200 rad dose or within 5 days of a $6,800 \mathrm{rad}$ dose.

Skanse (1948) discovered that the goitrogenic response of the chicken to TSH and thiouracil administration could be inhibited by large $(50 \mu \mathrm{c})$ but not small $(10 \mu \mathrm{c})$ doses of radioiodine. Doniach \& Logothetopoulos (1955) used this inhibition of the goitrogenic response to study the effects of ionising radiation on the rat thyroid. In rats simply given $30 \mu \mathrm{c}{ }^{131} \mathrm{I}$ there was a decrease in thyroid weight and an increase in follicular cell height indicating that cell hypertrophy had occurred presumably under a TSH stimulus secondary to radioiodine induced thyroid failure. The ${ }^{131} I$ uptake of these "compensated" glands was normal. If the rats were hemithyroidectomised there was a similar tracer ${ }^{131}$ I uptake but greater "compensatory" follicular cell hypertrophy than in the controls. Finally the normal goitrogenic response to propylthiouracil was decreased in the irradiated group and was accompanied by a marked reduction in mitosis although cell hypertrophy was not reduced. The high incidence of abnormal nuclear forms suggested that the loss of the ability to divide was due to chromosome damage.

Crooks, Greig, Macgregor \& McIntosh (1964) measured the degree of inhibition of the goitrogenic response in the rat brought about by various accurately measured doses of X-rays from an external source. They found progressive 
inhibition with increasing doses of X-rays although ${ }^{131} I$ uptake was unaffected by doses up to 1,600 rads. Histological examination of these glands was not carried out so that the contribution of cell division and cell hypertrophy to the total gland weight could not be assessed. However, their observations were in keeping with those of Doniach \& Logothetopoulos (1955) and their dose-response curve compatible with those obtained in vitro by Puck, Morkovin, Marcus \& Ceicura (1957) and in vivo by Hewitt \& Wilson (1961). Observations akin to those of Crooks and others (1964) were made by Al-Hindawi \& Wilson (1965) who also showed by tritiated-thymidine labelling that DNA synthesis was decreased in the irradiated cells which also had had a shortened half-life. In this connection the work of Weinbren, Fitschen \& Cohen (1960) is worthy of mention. They irradiated rat livers with doses of X-rays insufficient to cause immediate cell death. Many months later the animals were subjected to partial heyatectomy. When the irradiated cells attempted to make good the functioning hepatic cell mass by cell division they immediately died a "mitotic death". All those observations indicate that doses of radiation which markedly reduce reproductive capacity do not significantly impair the ability of the follicular cells to survive and hypertrophy and the capacity of the whole gland to function normally. Therefore the mechanisms involved in cell division are more radiosensitive than those responsible for cellular viability, hypertrophy, and function.

The clinical implications of these observations are clear if extrapolation to the human situation is justified. A dose of radiation sufficient to have a significant rapid effect on total gland function, either by killing cells or rendering them functionless will leave exceedingly few cells reproductively intact. In these circumstances indefinite continuance of an adequate functioning cell mass is impossible. In other words, a dose of ${ }^{131}$ I sufficient to bring about a rapid decrease in thyroid function is likely to bring about thyroid gland failure in the long term due to accelerated cell death and failure of cell replacement.

The conflict between the slow control of symptoms and late onset of hypothyroidism described by Crooks (1965) can therefore be explained on the basis of the above observations. However they still do not answer the critical question of whether a radiation-induced partial thyroidectomy or its functional equivalent can be achieved or not. More detailed quantitative information about the postirradiation patterns of cell behaviour is needed. However, for an insight into the possible patterns of cell behaviour after irradiation we can turn briefly to the more ideal (but less realistic) radiobiological studies carried out in vitro.

\section{In Vitro Observations}

Fuck (1959) put tissue culture on a new rooung with the development of methods ror maincalning cells in vitro whose chromosome structure, biochemical behaviour and genetic relationships can be compared with normal cells in their normal environment. On this basis he was able to construct dose-response curves for reproductive integrity for a variety of human cells grown in vitro. Hewitt \& Wilson (1961) reported their dose-response curves for various tumour cells in animals. 'I he cells were irradiated in vivo and cultured in vivo by injection into test animals. The dose-response curves for all the tumour cells tested by Hewitt and Wilson (1961) were all very similar to one another and to those found by Puck, Morkovin, Marcus \& Ceicura (1957) and Morkovin \& Feldman (1960). The fact that similar quantitative responses were obtained by different investigators working with different cell types under different conditions argues that the phenomena are of such a fundamental nature as to be applicable to the human situation.

It must be appreciated however that the situation is more complex than is indicated by the experiments quoted above which concern themselves in the main with the effect of radiation on one aspect of cell activity, i.e. the ability to divide an indefinite number of times. In contrast Sinclair (1964) reported the induction of cell mutants which survived but grew more slowly than the reproductively intact cells and unirradiated controls. Thus after irradiation there exists a heterogeneous population with respect to cell division and this probably applies to every aspect of cell activity. This heterogeneity was also demonstrated by the experiments of Puck \& Marcus (1956), Tolmach \& Marcus (1960) and Tolmach (1961). They showed that radiation damaged cells may lyse before division, grow without division to form giant cells which ultimately die, or divide a limited number of times. Elkind, Han \& Volz (1960) also found that many of the damaged cells could divide a limited number of times, the number being inversely related to the dose of $\mathrm{X}$-rays. 


\section{Conclusions}

If nothing else the preceding discussion illustrates the complexity of dynamic events which follow irradiation of the cell population of a whole organ. Each individual effect such as immediate cell death; or loss of reproductive capacity will have its own dose-response characteristics. However, many radiation effects are probably interrelated in terms of combinations of genetic damage so that as the dose of radiation increases it is unlikely that the proportions of the various types of damaged cells will follow a simple pattern.

Philp (1965) reported a model in which the cells of the rat thyroid divide expotentially after goitrogen administration. This provides for the first time a population of normal mammalian cells in their normal environment undergoing division at a constant and measurable rate. Similar experimental conditions have previously only been available in bacterial or tissue culture. This model is now being used to study the various patterns of cell behaviour after graded doses of X-rays. It is anticipated that the results of these investigations will indicate the feasibility of a radiation-induced nartial thyroidectomy or its functional equivalent. On the answer to this question hinges the future pattern of applications of radioiodine as a therapeutic agent.

\section{REFERENCES}

Al-Hindawi, A. Y., and Wilson, G. M. (1965): The Effect of Irradiation on the Function and Survival of Rat Thyroid Cells, Clin. Sci., 28, 555.

BACO, M. and AleXANDER, P. (1961): Fundamentals of Radiobiology, 2nd Ed., Chaps. 1-6. Oxford, London, etc.: Pergamon Press.

BELING, U., and EINHORN, J. (1961): Incidence of Hypothyroidism and Recurrences Following ${ }^{132} \mathrm{I}$ Treatment of Hyperthyroidism, Acta. radiol. (Stockh.), 56, 275.

Blumgart, H. L., Freedburg, A. S., and Buka, R. (1948): Treatment of Euthyroid Cardiac Patients by Producing Myxoedema with Radioactive Iodine, Proc. Soc. exp. Biol. (N.Y.), 67, 190.

Blumgart, H. L., FreedburG, A. S., and Kurland, G. S. (1955): Treatment of Incapacitated Euthyroid Cardiac Patients with Radioactive Iodine, J. Amer. med. Ass., 157, 1.

Crooks, J., Greig, W. R., Macgregor, A. G., and McINTosh, J. A. R. (1964): A Quantitative Method of Measuring the Effects of X-Irradiation on the Growth and Function of the Rat Thyroid Gland, Brit. J. Radiol., 37, 380.

Crooks, J. (1965): Radioactive Iodine Therapy in the Treatment of Thyrotoxicosis, Proc. Fifth Inter. Thyroid Conf. (Rome), p. 1208. Edited by Cassano, C., and Andreoli, M. New York and London: Academic Press.

Curran, R. C., ECKert, H., and Wilson, G. M. (1958): The Thyroid Gland after Treatment of Hyperthyroidism by Partial Thyroidectomy or 121Iodine, J. Path. Bact., 76, 54.
Dobyns, B. M., Vickery, A. L., Maloof, F., and Chapman (1953): Functional and Histological Effects of Therapeutic Doses of Radioactive Iodine on the Thyroid of Man, J. clin. Endocr., 13, 548.

DONIACH, I. (1953): Effect of Radioiodine Alone and in Combination with Methylthiouracil upon Tumour Production in the Rat's Thyroid Gland, Brit. J. Cancer, 7, 181.

DONIACH, I., and LOGOTHETOPOULOS, J. H. (1955): Effect of Radioactive Iodine on the Rat's Thyroid Function, Regeneration and Response to Goitrogens, Brit. J. Cancer, 9, 117.

DunN, J. T., and Chapman, E. M. (1964): Rising Incidence of Hypothyroidism after Radioactive Iodine Therapy in Thyrotoxicosis, New Engl. J. Med., 271, 1037.

ECKeRT, H., GREEN, M., KilPatrick, R., and Wilson, G. M. (1960): Thyroid Function after the Treatment of Thyrotoxicosis by Partial Thyro:dectomy or ${ }^{131}$ Iodine, Clin. Sci., 20, 87.

Elkind, M. M., HaN, A., and Volz, K. W. (1963): Radiation Response of Mammalian Cells grown in Culture, J. nat. Cancer Inst., 30, 705.

Findlay, D., and Leblond, C. F. (1948): Partial Destruction of the Rat Thyroid with large Doses of Radio-iodine, Amer. J. Roentgenol, 59, 387.

Freedburg, A. S., Kurland, G. S., and Blumgart, H. L. (1952): The Pathologic Effects of ${ }^{131} \mathrm{I}$ on the Normal Thyroid Gland in Man, J. clin. Endocr., $12,1315$.

Goldberg, R. C., Chaikoff, I. L., Lindsay, S., and Feller, D. D. (1950): Histopathological Changes induced in the Normal Thyroid and Other Tissues of the Rat by Internal Radiation with various doses of Radioactive Iodine, Endocrinology, 46, 72.

GoldberG, R. C., and Chaikoff, I. L. (1952): Induction of Thyroid Cancer in the Rat by Radioactive Iodine, Arch. Path., 53, 22.

Goolden, A. W. G. (1964): Radioactive Isotopes of Iodine and their Application in "The Thyroid Gland" vol. 1, Edited by Pitt-Rivers, R., and Trotter, W. R. London: Butterworth.

Green, M., Fisher, M., Miller, H., and Wilson, G. M. (1961): Blood Radiation Doses after ${ }^{131}$ I Therapy of Thyrotoxicosis: Calculations with Reference to Leukaemia, Brit. med. J., ii, 211.

GreEN, M., and Wilson, G. M. (1964): Thyrotoxicosis treated by Surgery or Iodine-131. With Special Reference to the Development of Hypothyroidism, Brit. med. J., i, 1005.

Greig, W. R., Boyle, J. A., Buchanan, W. W., and SHEENA Fulton (1965): Clinical and Radiobiological Observations on Latent Effects of X-irradiation on the Thyroid Gland, J. clin. Endocr., 25, 1009.

Greig, W. R., Crooks, J., and Macgregor, A. G. (1966): Clinical and Radiobiological Consequences of Thyroid Irradiation, Proc. roy. Soc. Med. (To be Published).

Groover, R. A., Christie, A. C., Merritt, E. A., COE, F. O., and MCPEAK, E. M. (1929): Roentgen Irradiation in the Treatment of Hyperthyroidism J. Amer. med. Ass., 92, 1730.

HAYES, M. R. J. (1927): A Study of X-ray Treatment of One Hundred Cases of Graves Disease, Brit. J. Radiol., 32, 64.

HewitT, H. B., and Wilson, C. W. (1961): Survival Curves for Tumour Cells Irradiated in vivo. Ann. N.Y. Acad. Sci., 95, 818. 
Hollingworth, D., Hamilton, H. D., Tamagaki, H., and BEEBE, G. W. (1963): Thyroid Disease: A Study in Haroshima, Japan. Medicine (Baltimore), 42, 47.

LeVene, M. B., ANDrews, G. A., and KNiseley, R. M. (1955): Large Doses of ${ }^{131} I$ in Dogs: Radiation Dosage Correlated with Histologic and Autoradiographic Changes, Amer. J. Roentgenol, 73, 88.

LindSAY, S., Dailey, M. E., and Jones, M. D. (1954) : Histologic Effects of Various Types of Ionising Radiation on Normal and Hyperplastic Human Glands, J. clin. Endocr., 14, 1179.

McGirr, E. M., Thompson, J .A., Murray, I. P. C. (1964): Radioiodine Therapy in Thyrotoxicosis: A Review of 908 Cases, Scot. med. J., 9, 505.

McQuade, H. A., Seaman, W. B., Porporis, A. A. (1956): Electron Microscopy of Irradiated Cells of the Follicular Cells of the Rat Thyroid, Radiat. Res., 4, 532.

Means, J. H., DeGroot, L. J., and Stanbury, J. B. in The Thyroid and its Diseases p. 233, Published by the Blakiston Division. New York, Toronto and London: McGraw-Hill Book Company.

Morkovin, D., and Feldman, A. (1960): End Point of One of the Actions of Radiation on Living Tissue important in Radiation Therapy and in Acute Radiation Syndrome, Brit. J. Radiol., 33, 197.

Philp, J. R. (1965): The Growth Pattern of Thyroid Follicular Cells under a Goitrogenic Stimulus, Scot. med. J., 10, 488.

Pochin, E. E. (1960): Leukaemia Following Radioiodine Treatment of Thyrotoxicosis, Brit. med. J., ii, 1545 .

Puck, T. T., and Marcus, P. I. (1956): Action of X-rays on Mammalian Cells, J. exp. Med., 103, 653.

Puck, T. T., Morkovin, D., Marcus, P. I., and CeICURA, S. J. (1957): Action of X-rays on Mammalian Cells. II. Survival Curves of Cells from Normal Human Tissues, J. exp. Med., 106, 485.
Puck, T. T. (1959): Quantitative Studies on Mammalian Cells in Vitro, Rev. mod. Physics, 31, 433.

Quimby, E. H., and Werner, S. C. (1949): Late Roentgen Radiation Effects in Roentgen Ray $\varrho$ Therapy for Hyperthyroidism, J. Amer. med. Ass., $\subset$ 140, 1046.

Sheline, G. E., Lindsay, S., and Bell, H. G. (1959): Occurrence of Thyroid Nodules in Children follow- 0 ing Therapy with Radioiodine for Hyperthyroidism, J. clin. Endocr., 19, 127.

Sinclair, W. K. (1964): X-ray Induced Heritable $\frac{5}{\vec{\gamma}}$ Damage (Small Colony Formation) in Cultured @ Mammalian Cells, Radiat. Res., 21, 584.

SKaNSE, B. N. (1948): Biologic Effect of Irradiation by Radioactive Iodine, J. clin. Endocr., 8, 707.

Smith, R. N., and Wilson, G. M. (1965): A Clinical $\overrightarrow{\vec{c}}$ Trial of Different Doses of ${ }^{131} \mathrm{I}$ in the Treatment of ${ }^{\omega}$ Thyrotoxicosis. Proc. Fifth International Thyroid Conference (Rome), p. 1152. Edited by Cassano, C., and Andreoli, M. New York and London: Academic Press.

St. Aubin, P. M., Kniseley, R. M., and Andrews, G. A. (1957): External Irradiation of the Thyroid $\mathscr{0}$ in Dogs, Amer. J. Roentgenol, 78, 804.

TolmaCH, L. J., and Marcus, P. I. (1960): Development of X-ray Induced Giant Hela Cells, Exp.음 Cell Res., 20, 350.

Tolmach, L. J. (1961): Growth Patterns in X- $\vec{c}$ irradiated Hela Cells, Ann. N.Y. Acad. Sci., 95, 743.

Walters, A. M., ANSON, B. J., and IVEY, A. C (1931): The Effects of X-rays on the Thyroid and Parathyroid Glands, Radiology, 16, 52.

Weinbren, K., Fitschen, W., and COHEN, M. (1960) The Unmasking by Regeneration of Latent Irradi tion Effects in the Rat Liver, Brit. J. Radiol., 3; 419.

Werner, S. C., Gittelshon, A. M., and Brill, A. B. (1961): Leukaemia Following Radioiodine Therapy of Thyrotoxicosis, J. Amer. med. Ass., 177, 646. 